\title{
Inter-layer Adhesion Performance of Steel Packaging Materials for Food Cans Under Retort Conditions
}

\author{
Andrew Allman ${ }^{1} \cdot$ Eifion Jewell $^{1}$ (i) $\cdot$ Arnoud de Vooys $^{2} \cdot$ Rachel Hayes $^{3}$
}

Received: 23 October 2017 / Accepted: 7 April 2018 / Published online: 17 May 2018

(c) The Author(s) 2018

\begin{abstract}
The steel packaging industry faces the dual challenge imposed by legislation to eradicate the use of Chrome(VI) from substrate manufacture and the removal of Bisphenol-A (BPA) from the organic lacquer at the point of food contact. The paper reports on an experimental investigation into the quality of adhesion between the coatings and substrates as a result of the retort process, typically the harshest conditions to which the materials will be exposed. In terms of adhesion, the novel Chrome(III) substrates show promise when compared with current Chrome(VI) substrate. There is a significant reduction in the adhesion of the polyester-based Bisphenol-A non-intent lacquers compared to the incumbent epoxy-phenolic lacquers. Adhesion performance is lower with an increase in retort temperature and time of exposure. The adhesion further reduces in mild acidic and saline conditions. The reduction in adhesion post-retort is attributed to the sensitivity of the polyester-based BPANI lacquers to water vapour absorption. The process reversible nature of the adhesion loss indicates that, at short timescales, the adhesion loss is a result of polyester hydrolysis. Acidic and saline solutions also lead to a reduction in adhesion as a result of metal surface corrosion. The paper has impact on producers, fillers and consumers of steel packaging foodstuffs.
\end{abstract}

Keywords Packaging steel $\cdot$ BPANI $\cdot$ Chrome $(V I)$-free substrates $\cdot$ Adhesion

$\begin{array}{ll}\text { Abbreviations } \\ \text { BPA } & \text { Bisphenol-A } \\ \text { BPANI } & \text { Bisphenol-A non-intent } \\ \text { EP } & \text { Epoxy-phenolic } \\ \text { ECCS } & \text { Electrochromic-coated steel } \\ \text { TCCT } & \text { Trivalent chromium-coated technology }\end{array}$

\section{Introduction}

Steel has been used for metal packaging applications for many years, providing improved product lifetimes and protection against physical and chemical damage [20]. Primarily, two coated steels are used for food can applications, the first being tinplate, having a layer of tin approximately $0.2-2 \mu \mathrm{m}$ thick, the other being electrochromium-coated

Eifion Jewell

e.jewell@swansea.ac.uk

1 College of Engineering, Swansea University, Swansea, UK

2 TATA Steel, R\&D IJmuiden, IJmuiden, Netherlands

3 CROWN Packaging Manufacturing UK Limited, Wantage, Oxon, UK steel (ECCS) which has a layer of chromium/chromium oxide approximately $10-30 \mathrm{~nm}$ thick on the surface of the steel [5].

REACH legislation has dictated that use of $\mathrm{Cr}(\mathrm{VI})$ will be restricted, impacting industrial processes, including the production of ECCS [11], thus leading to novel methods of chromium coating steel with the aim of providing a comparable substrate to ECCS. To this end, TATA Steel has developed Trivalent Chrome-Coated Technology (TCCT), eliminating the use of $\mathrm{Cr}(\mathrm{VI})$ in production through using Cr(III) salts for electroplating [24].

Lacquers are used to prevent any potential reactions that may occur between the substrate metal and the food product [17], thus increasing the life span of the packaging and the product. Bisphenol-A (BPA) is a key monomer in epoxyphenolic coatings used within the canning industry, proving to be a robust coating. Legislation has dictated the removal of BPA from food contact materials in some territories within Europe, hence new lacquers have been developed to comply with legislation. While BPA may be present in trace amounts within these newly developed coatings, it is not intentionally added during manufacture, and is known to be measurable in many human bodily fluids [23]. Polyesters have been proven commercially as BPA non-intent (BPANI) 
alternatives to traditional coatings for food contact application, and are in use, as are other chemistries. As with all developments in coatings of this nature, migration studies have also been conducted on polyester coatings, showing little risk [18].

The combination of novel chromium-coated steel and BPANI lacquers provides a new mechanism of adhesion that is currently not well understood, nor are the behaviours of the system under the conditions experienced through the canning process and hence characterisation is required. The phenomenon of lacquer adhesion occurs through various bonding mechanisms including van der Waals forces, electrostatic forces and induction forces [1], the mode of which will change depending on the substrate and applied coating [12]. While adhesion under dry conditions is important through the processes that occur in can manufacture before filling, adhesion under wet conditions also proves key for a can's internal lacquer as it must be able to withstand the heat treatment of retorting while exposed to different formulations of foodstuffs [19], followed by prolonged exposure to the contents over periods extending through the entire shelf life of the can [15].

The effect of the retort process parameters on the adhesion quality is a consequence that needs to be understood. Different temperatures are used to sterilise different products, above $100{ }^{\circ} \mathrm{C}$ [22], typically for canned goods between 110 and $140{ }^{\circ} \mathrm{C}$ in pressure cookers [7]. This range in temperatures and pressures means that any coating/substrate system must be resilient to these parameters, providing an effective chemical and physical barrier. Knowing the quality of adhesion through the changing parameters allows understanding as to how the coating system work and the applications it might be suitable for. Due to the reliable nature of the adhesion of epoxy-phenolic coatings on ECCS, little literature is available on the subject, but the novel systems being developed present avenues for understanding.

The primary aims of the investigation were to establish relationships between the behaviour of a BPANI coating before and after retorting, whether this be in terms of adhesion quality, mechanical properties or the effect that a simulant solution might have on the system.

\section{Materials and Methods}

Substrate materials were obtained from TATA Steel. Two incarnations of chromium-coated steel produced using $\mathrm{Cr}$ (III) species (TCCT) were used, along with ECCS produced in the traditional manner using $\mathrm{Cr}(\mathrm{VI})$, as a reference substrate. The " 61 " iteration of TCCT is produced through a double-layer electroplating process, whereas " 63 " is a triple "layer" where the outer layer is intentionally a chromium oxide layer.
The substrate characteristics are summarised in Table 2 and show how 63 and ECCS have a higher level of chromium oxides at the surface. In addition to this, they do not show chromium carbide that is present in 61 to the same level, present in the TCCT variants, owed to the deposition process differing to that of ECCS. Iron, in the metallic state is present in 61 and to some degree in 63 although this is reduced. XPS measurements were averages of 9 points measured on each substrate, within an accuracy of $0.05 \%$.

This shows that the technical challenge of providing materials with similar surface characteristics (species and roughness) has largely been achieved, although as the samples of TCCT 61 and 63 were obtained from pilot and not production facilities, the consistency of coating across and through the coil is less well established. The ECCS characteristics are in line with the literature [5], while the characteristics of TCCT differ from ECCS as shown in Table 1. While metallic iron is not detectable through XPS on the ECCS surface, it is present for the pilot line TCCT materials shown here, in addition to this there is an appreciable increase in the amount of chromium carbide on the surface when compared to ECCS.

Two commercial lacquers provided by Metlac, a polyester BPANI and an epoxy-phenolic, were used. These represent two commercially available materials, the former being a relative new comer to the market. For both of the supplied coatings, the manufacturer's curing instructions were followed. The lacquer was coated to the substrate using an RK automatic Meyer bar coating system, resulting in a coating thickness of 10-12 $\mu \mathrm{m}$. The coating was cured using a Thieme belt dryer, comparable to that used in the industrial process, for a 15-min residence time. This resulted in dry coating weights of 9 and $5 \mathrm{~g} / \mathrm{m}^{2}$ for the BPANI and epoxyphenolic coatings, respectively. 50 samples of each substrate were prepared on a $45 \times 120 \mathrm{~mm}$ format. To prevent water ingress on the edges of the samples that would not be present in the finished can, the edges were sealed with an epoxy sealant to cover the exposed interface between lacquer and substrate.

10 test samples were submerged in a range of simulant solutions (detailed in Table 2), as a means of assessing how

Table 1 Substrate surface properties

\begin{tabular}{llll}
\hline & ECCS & TCCT 61 & TCCT 63 \\
\hline Roughness Ra $(\mu \mathrm{m})$ & 425 & 428 & 421 \\
Cr metal $(\%)$ & 2.5 & 8.9 & 1.4 \\
CrOx $(\%)$ & 3.6 & 25.0 & 27.1 \\
Fe $(\%)$ & 0 & 0.38 & 0.02 \\
Chromium carbide & 0.5 & 4.8 & 5.9 \\
\hline
\end{tabular}

Surface roughness measured through white light interferometry, surface chemistry analysed through XPS 
Table 2 Simulant solution compositions and typical represented foodstuffs

\begin{tabular}{ll}
\hline Simulant solution composition & Typical foodstuff \\
\hline $1 \% \mathrm{NaCl}$ (standard brine) & Peas or beans \\
$1 \% \mathrm{NaCl}, 1 \%$ acetic acid (acidified brine) & Gherkins or onions \\
$1 \%$ lactic acid (carbohydrate fermentation) & Sauerkraut or dairy products \\
$0.25 \% \mathrm{NaCl}, 0.25 \%$ citric acid (acidified brine) & Salsify \\
\hline
\end{tabular}

each lacquer/substrate combination might behave when exposed to foodstuffs. Samples were put into a beaker filled with simulant, into a CertoClav MultiControl 2 autoclave, Fig. 1a, used to reproduce the temperature/pressure cycle that occurs when cans are sterilised under the nominal conditions of $121{ }^{\circ} \mathrm{C} / 1.06$ bar for $90 \mathrm{~min}$, Fig. 1b. Where the temperature of the retort was changed, the same cycle was used, but the sustained temperature was changed.

Samples removed from the chamber were dried using lint-free cloth to remove surface water/solution and the adhesion measured using a Sheen Instruments BS3359 scratch tester operated with accordance to ISO 15181:2011 (BSI [4]. Scratch testing provides a quantitative analysis of the adhesion force of a given coating, somewhat removing the subjective nature of other adhesion test methods such as cross hatch testing, and is suitable for thin films, requiring no chemical interaction with the surface as would be the case in a pull off test, hence minimal chemical disruption of the organic coating [2]. Repeated measurements were shown to be $\pm 0.25 \mathrm{~N}$ in terms of adhesion force. The scratched area was assessed using optical microscopy and the adhesion force recorded as the highest force at which the scratch would still 'pass', i.e. the film of coating is still intact and covering the scratch area. The adhesion values presented represent a mean of ten measurements. Knoop hardness was measured using a Zwick Indentec $\mathrm{ZH} \mu$ microhardness tester, in accordance with ISO 6441-1. A standard error of was found to be 5.3\%.

Since samples are being removed from the wet environment, the time frame of opportunity for considering the measurement to be "post-retort adhesion" is inherently small. A study was carried out to correlate adhesion force with time removed from the true wet environment; for this work, samples were kept in open air and adhesion measurements taken at intervals up to 7 days.

Thermogravimetric analysis was used to give an insight into the amount of simulant solution absorbed into the coating, applied to a glass substrate to isolate the coating from interactions with the substrate. Experiments were carried out with the thin film coating. TGA experiments were conducted using a Perkin Elmer thermogravimetric module Pyris 1 TGA. Results were obtained using a heating rate of $10{ }^{\circ} \mathrm{C} / \mathrm{min}$ from 20 to $130{ }^{\circ} \mathrm{C}$, maintaining a temperature of $130{ }^{\circ} \mathrm{C}$ for $30 \mathrm{~min}$, with a sample mass of approximately $20 \mathrm{mg}$ in a $50 \mu \mathrm{L}$ ceramic pan. Quoted repeatability for the device is $\pm 0.1 \mathrm{mg}$ which represents $\pm 5 \%$ of the sample mass.

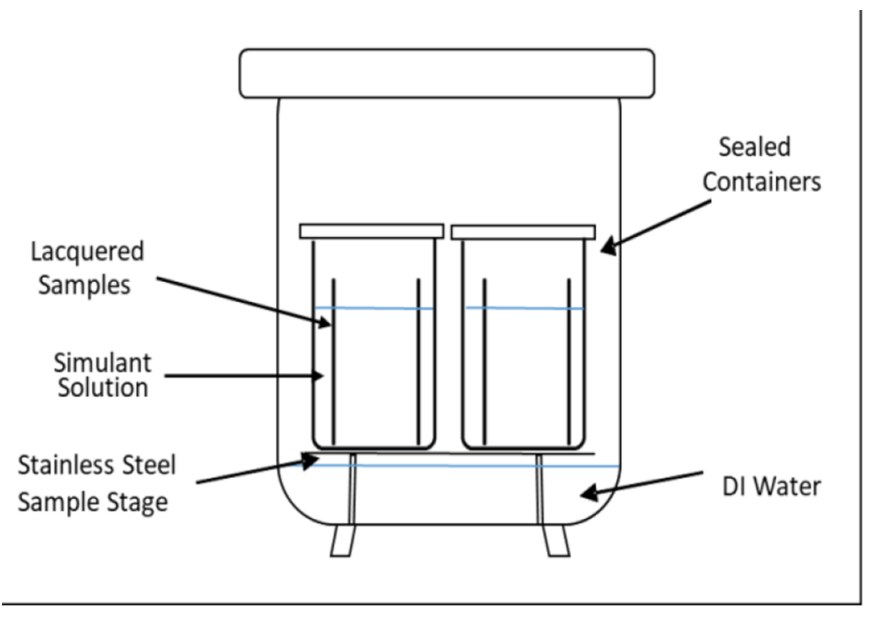

(a)

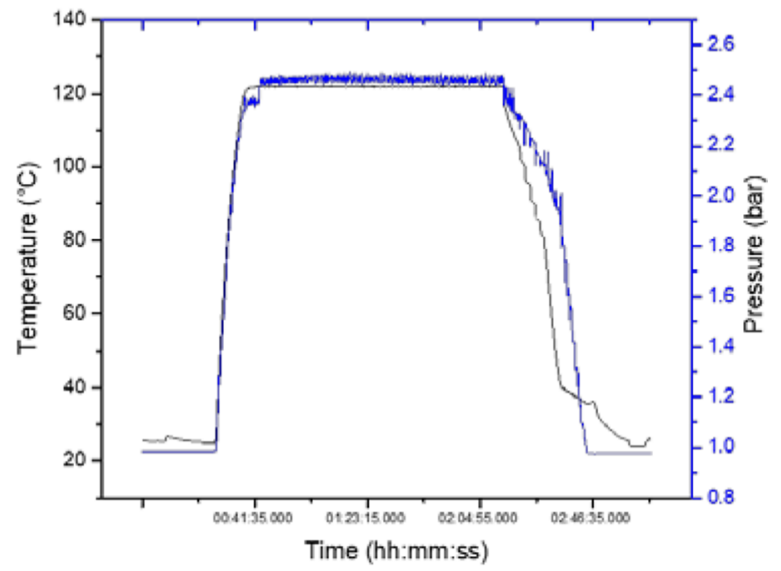

(b)

Fig. 1 a Internal schematic of retort apparatus. b Time-temperature profile experienced by the samples in the autoclave measured using TMIOrion PicoVACQ pressure and temperature loggers 


\section{Results}

Dry adhesion measurement provides a means of characterising the substrate/lacquer bonding in its virgin coated state. It is used by can manufactures as a QC tool for the given substrate/lacquer combination as it can be an indicator of substrate surface contamination or incorrect lacquer curing and can also provide valuable information on any prospective adhesion issues during the can-forming process. The adhesive performance of the BPANI materials is below that of the current benchmark epoxy-phenolic technology, Fig. 2, showing approximately $10 \%$ reduction in adhesion force before exposure to forming or retorting. This is in line with the observations in the limited literature available [16]. The dry adhesion of the 61 (higher surface chromium) substrate is a little higher than the incumbent ECCS material while the 63 (lower surface chromium) is a little lower.

There is significant interaction between the retort simulant, the substrate and the subsequent lacquer adhesion, Fig. 3. The most significant single effect is the lacquer which consistently shows a lower level of adhesion (between 50 and 60\%) for the BPANI material compared to the epoxy-phenolic material on the ECCS substrate. Within the BPANI group of materials, the impact of the substrate is small in comparison although some trends are observed.

The measurements carried out using DI water as a simulant act as a baseline, showing how water will affect with the coating/substrate interface, without the addition of the salts and acids of other simulant solutions. The presence of any simulant in the water generally causes a reduction in the adhesion with lactic acid providing the greatest reduction in adhesion. With the more aggressive acidic environments, it is proposed that the reduction is adhesion is also a result of acidic species migrating through the lacquer to cause defects or potentially corrosion at the substrate/ film interface $[3,8]$. The acid may also have a potential for acid-catalysed ester hydrolysis to occur, degrading the coating and thus reducing the coating barrier properties. When $\mathrm{NaCl}$ is present in combination with the citric acid at the same concentration, the effect on adhesion is similar to that shown by the pure DI water simulant. There is some evidence in the literature which indicates some level of inhibitor performance from fruit acids $[6,14,25]$ although this has not been proven here.

The retort process also changes the adhesion failure mechanism as measured by scratch testing. Retorted samples show a greater degree of tearing of the coating as opposed to the piercing. The area of lacquer removed on the retorted sample is also around twice of that observed for the dry adhesion tests, Fig. 4. This would suggest both a reduction in the lacquer/substrate bond strength and also a degree of plasticisation within the coating.

There is also evidence of change in physical characteristics of the BPANI material when the Knoop hardness of the material is examined, Fig. 5. In each instance the BPANI Knoop hardness reduces significantly to $95 \%$ of its original value and the inclusion of the simulant further reduces the Knoop hardness. This behaviour is attributed to a chemical
Fig. 2 Dry adhesion characteristics of the three substrate and two coating systems

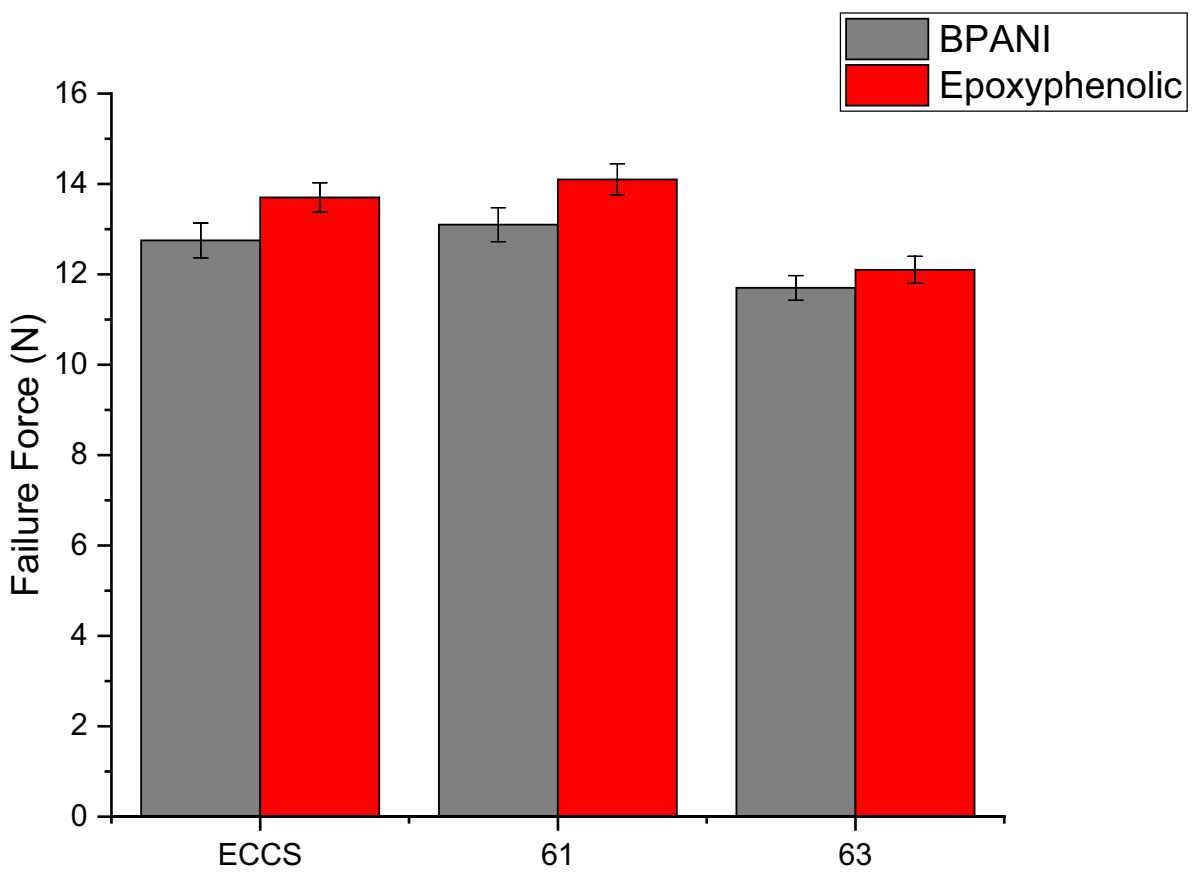


Fig. 3 The impact of simulant on measured wet adhesion for an exposure of $1.5 \mathrm{~h}$ at $121^{\circ} \mathrm{C}$ Pre-retort adhesion failure of each system is represented by the horizontal lines

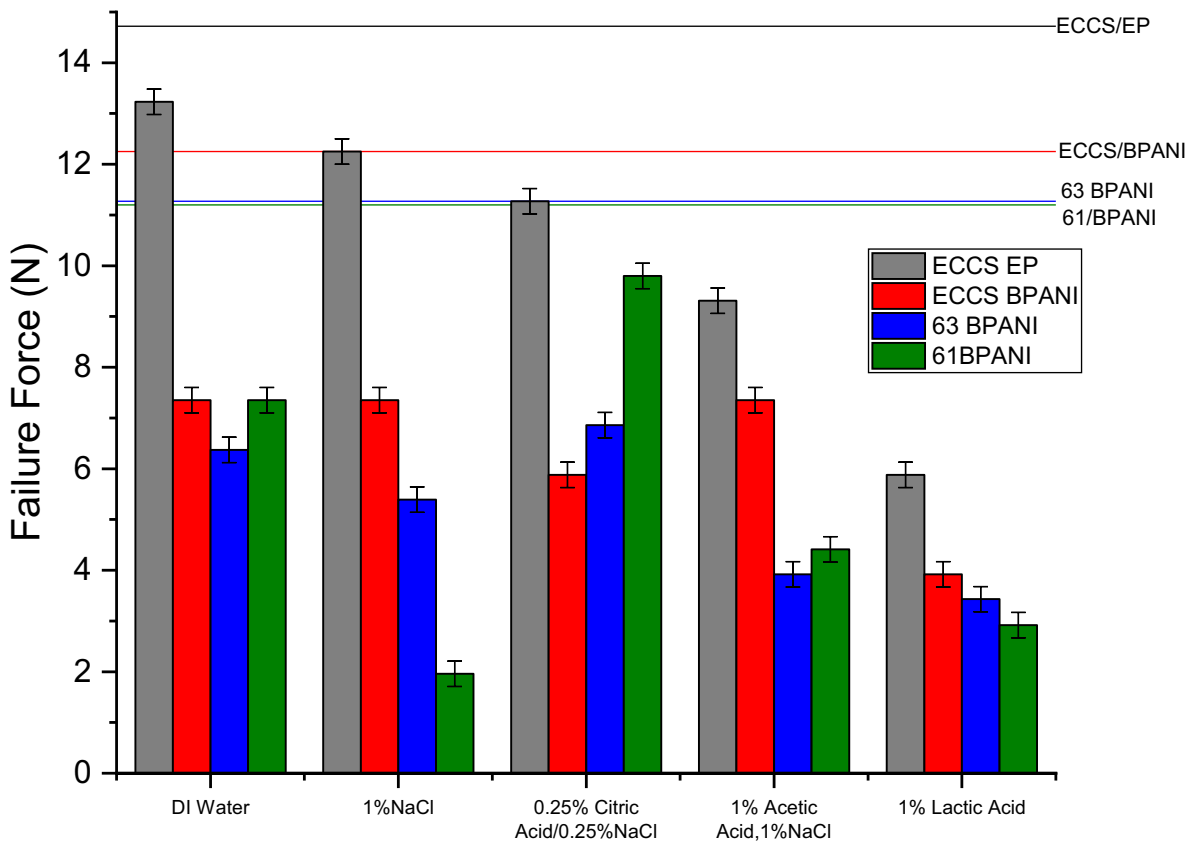

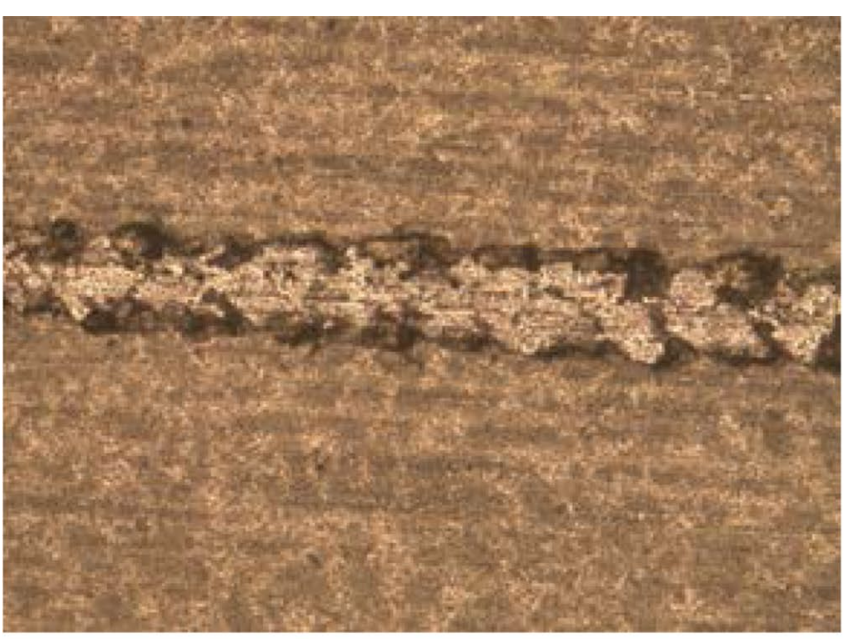

(a)

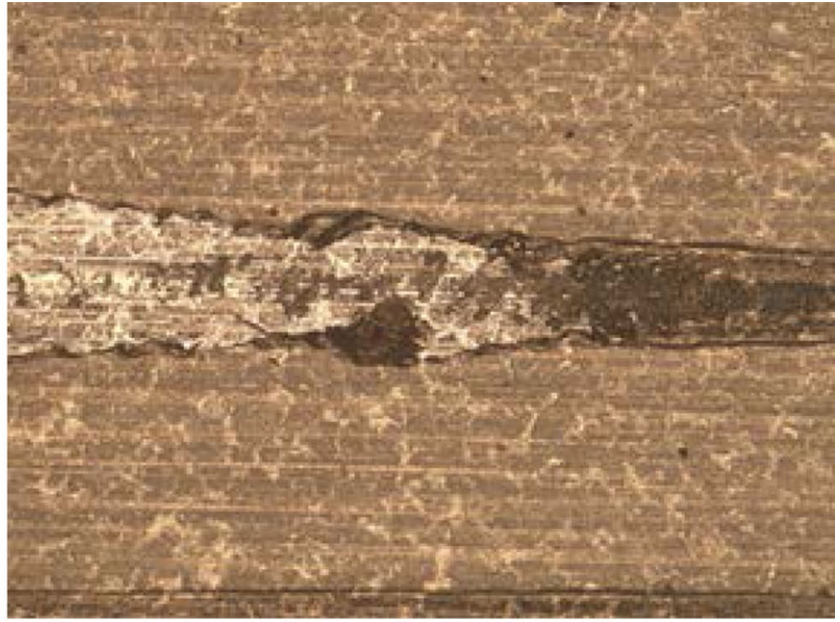

(b)

Fig. 4 Optical microscopy images showing scratch adhesion failure $\mathbf{a}$ under dry conditions and $\mathbf{b}$ after retort in DI water

change of the coating when the simulant composition concentration is increased.

It is proposed that the reduction observed in the BPANI materials is primarily caused by the polyester readily undergoing absorption where $\mathrm{H}_{2} \mathrm{O}$ is "absorbed" into the polyester bulk [9], with oxygen, water and ionic species having the potential to migrate through the coating [13]. If such a mechanism were present then the process should exhibit some distinct properties; it should steadily increase with time of exposure and it should be reversible and this exposure to dry air should see the lacquer regain its adhesion (provided that substrate corrosion has not taken place). Thermo-gravimetric measurements of samples of coated substrate which have experienced incremental exposure to DI water at $121{ }^{\circ} \mathrm{C}$ show that there is a gradual increase in mass of the coating over increasing retort time, Fig. 6b. DI water was chosen to minimise additional chemical interaction with the lacquer and the substrate. This can be compared to Fig. 6a where the scratch testing results are presented for the same conditions, showing how with a longer retort time, there is a reduction in the adhesion failure force. The epoxy-phenolic coating remains at a consistently higher failure force, and a consistently lower water absorption, whereas the BPANI shows a much greater reduction in failure force and a higher water absorption. 
Fig. 5 Knoop hardness for the lacquer after the retort process for each simulant

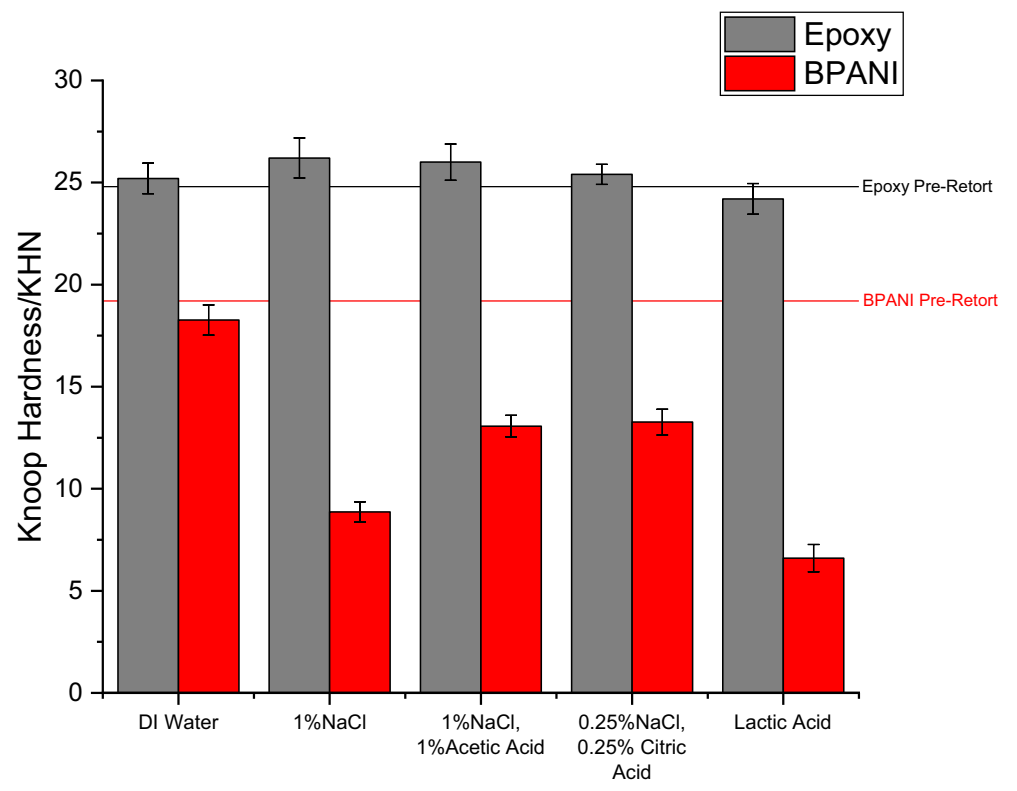

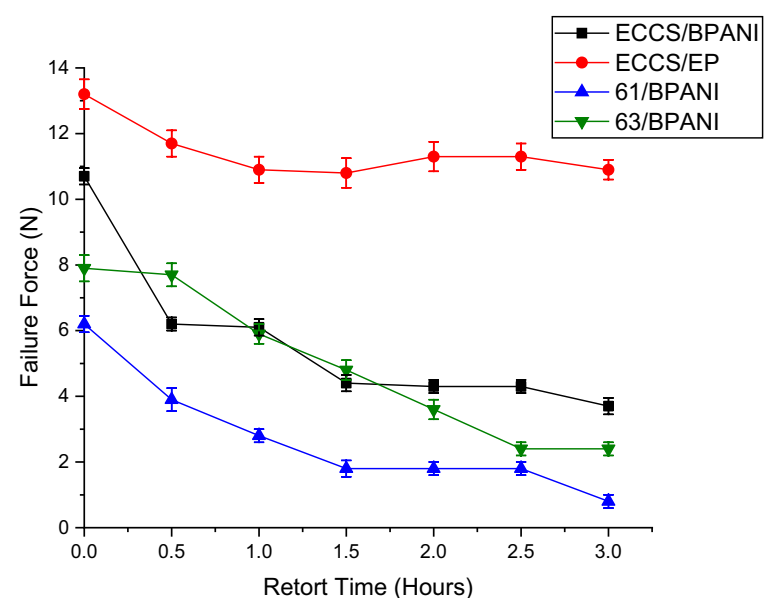

(a)

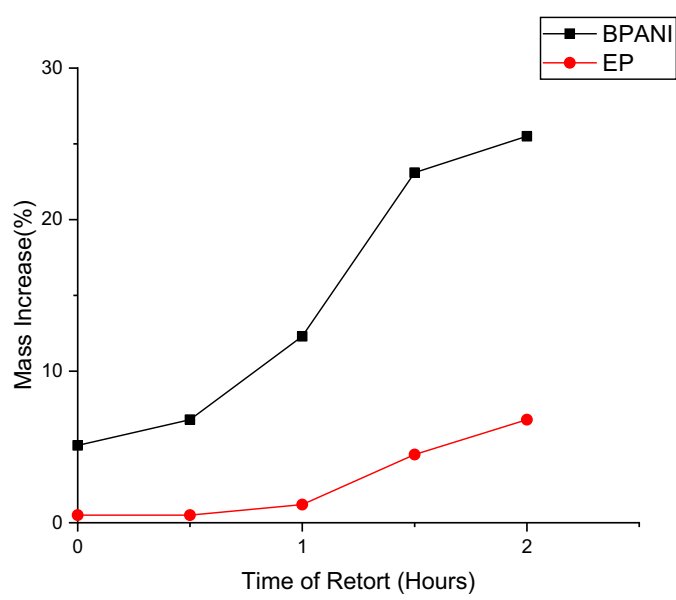

(b)

Fig. 6 a Relationship of retort plateau time with scratch failure force. b Mass increase of coated BPANI with exposure time at $121^{\circ} \mathrm{C}$

The impact of retort of the BPANI lacquer is further evidenced in Fig. 7 which depicts the impact of retort time on the adhesion on each substrate and both coatings. For all substrates, there is a significant reduction (between 50 and $90 \%$ ) in the adhesion with BPANI lacquer. There is a minimal reduction (between 10 and 15\%) in the adhesion for the epoxy-phenolic material on the ECCS substrate (Fig. 7a) but there is an appreciable reduction in adhesion on the novel $\mathrm{Cr}$ (III) substrates, Fig. $7 \mathrm{~b}$, c. It is proposed that change in adhesive behaviour between the substrate types is associated with the difference in surface chemistry as shown in Table 2, showing an increased level of exposed iron and also chromium carbide. These small areas of un-chromed substrate are likely to undergo corrosion in the relatively harsh environment that they are exposed to and this results in a weakening of the overall bond between the substrate and the lacquer. Being a fully developed commercial product, ECCS does not suffer from this characteristic. As the technology transitions from a pilot production to mature commercial production, this effect should reduce but will need to be confirmed through experimentation.

The reversible nature of the absorption into the BPANI coating is evident in Fig. 8 where the adhesion strength of samples has been measured over a 220 -h time period while the sample was exposed to a normal laboratory temperature of approximately $20{ }^{\circ} \mathrm{C}$, after removal from the retort environment. There is a gradual improvement in the adhesion, with force at point of failure increasing after 

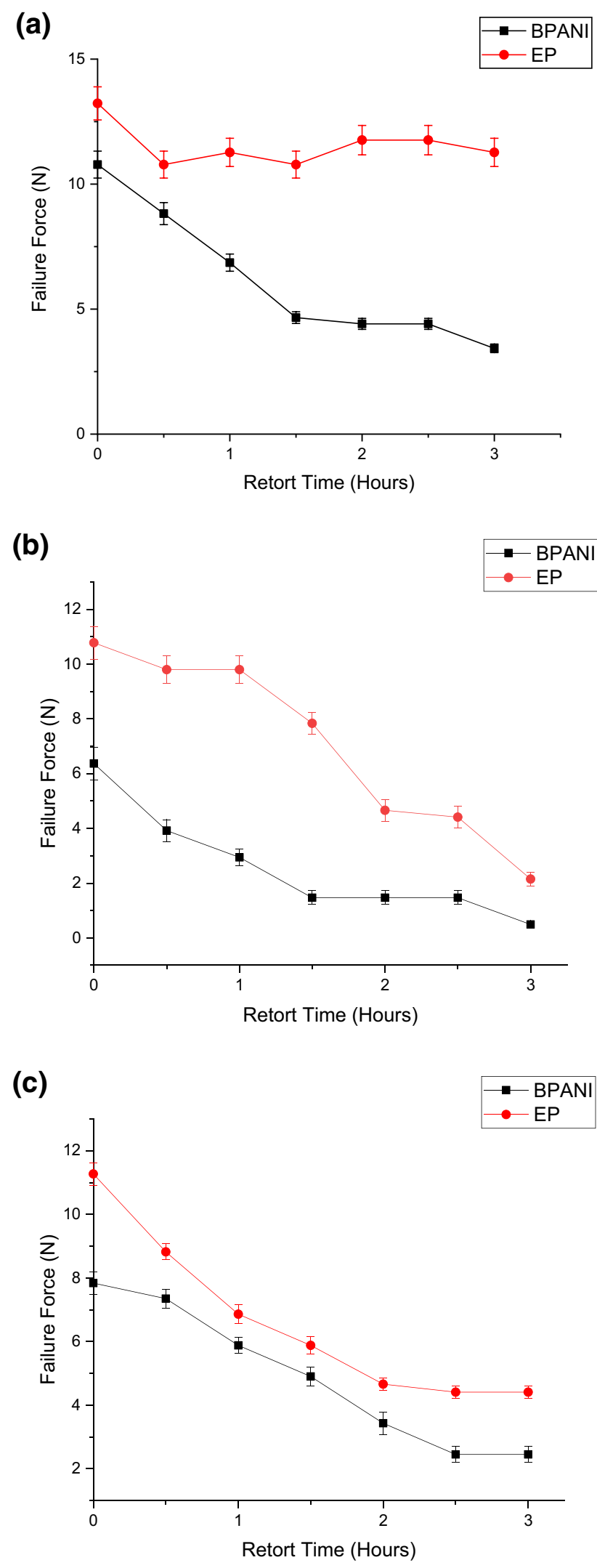

Fig. 7 The impact of retort time on the lacquer adhesion on each of the substrates
$15 \mathrm{~min}$, further increasing by $50 \%$ of the initially measured values within $1 \mathrm{~h}$ and increasing to $90-95 \%$ after $220 \mathrm{~h}$ in air. This 'relaxation' effect demonstrates that a high proportion of the adhesion failure is driven by a reversible effect. This has an impact on the measurement of adhesion in a QC or R\&D environment, all measurements taken outside of the 15-min removal window would not be an accurate representation of adhesion under wet conditions.

To examine the impact of any difference in retort process parameters, the failure force at sterilisation temperatures between 100 and $140{ }^{\circ} \mathrm{C}$ was assessed. Where there is an increase in the retort temperature, there is a significant decrease in the failure force. This is shown here in Fig. 9a and can be compared with TGA data in Fig. 9b. TGA data show that the thin film coating absorbs a greater quantity of simulant solution as the retort temperature increases. When compared with the epoxy-phenolic coating, the BPANI absorbs significantly more solution, at the maximum temperature tested, the BPANI absorbs more than $35 \%$ of its own mass in solution during the retort process. TGA results correlate with failure force results in that compared with results at $100{ }^{\circ} \mathrm{C}$, the failure force for the BPANI coating typically reduces to $50 \%$ of this value at $140{ }^{\circ} \mathrm{C}$ while the epoxy-phenolic coating reduces by approximately $20 \%$.

This absorption of water by the polyester film occurs for every simulant, Table 3 . Where $\mathrm{NaCl}$ is present in the simulant, the measured absorption is lower, potentially result of the $\mathrm{NaCl}$ being retained within the polyester post-drying, a phenomenon requiring further investigation. The mass loss in lactic acid is significantly higher indicating that the lactic acid has had a chemical impact on the BPANI material. It is postulated that the presence of the acid causes an acidcatalysed hydrolysis reaction, degrading the polyester to it alcohol/carboxylic acid components [10,21]. During the post-retort drying process, the boiling point of these components is such that they can leave the film producing a greater perceived loss of mass.

The net result of this acid catalysis of the polyester is to cause a substantial reduction in the adhesion, Fig. 10. At higher temperatures, there is also a reduction in the epoxyphenolic adhesion and this is a result of lactic acid and water diffusion through the film resulting in substrate corrosion at the lacquer/substrate interface. Some iron oxide corrosion was evident in all samples at the highest temperatures.

The relative importance of the substrate corrosion/lacquer integrity mechanisms on the coating/substrate failure changes with simulant chemistry and retort time/temperature. Future work should examine water absorption into the coating and its subsequent effect on the coating/substrate interface. Deformation of the steel, such as that experienced through can formation, is highly likely to alter the adhesion 
Fig. 8 The BPANI adhesion force with relation to post-exposure relaxation time



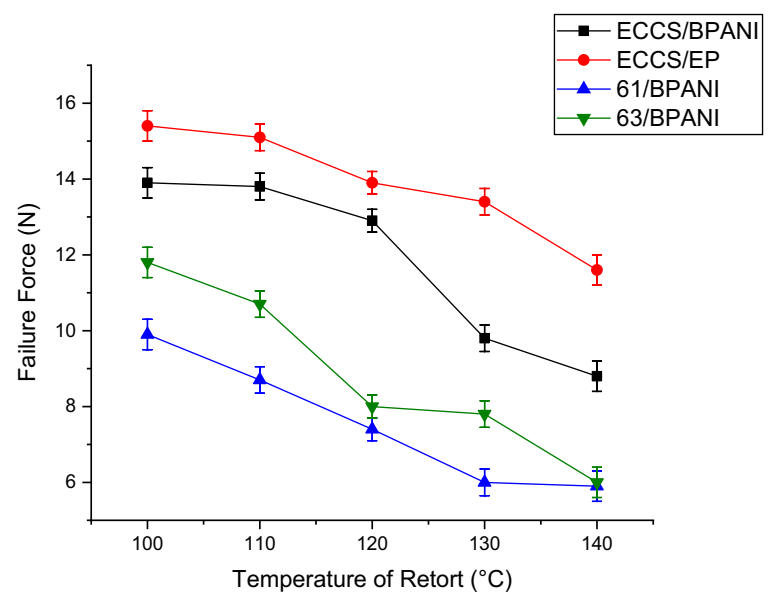

(a)

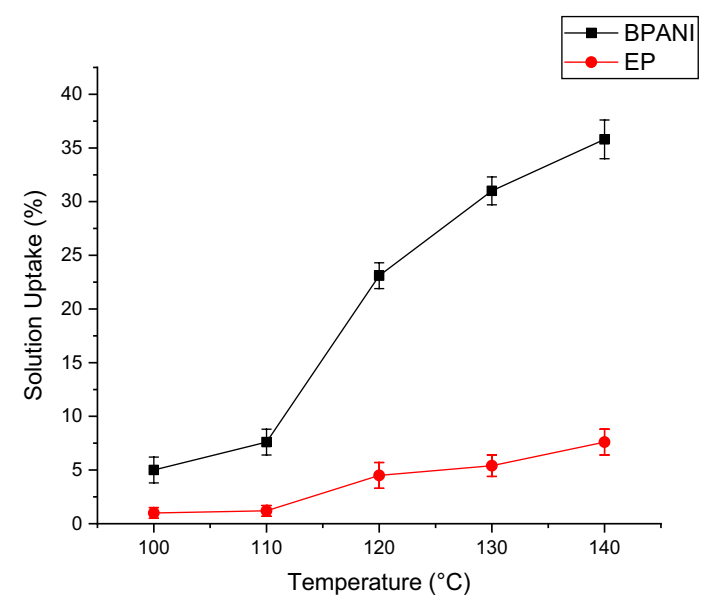

(b)

Fig. 9 Retort plateau temperature results for $\mathbf{a}$ scratch testing and $\mathbf{b}$ TGA experiments

Table 3 The impact of simulant on the percentage mass loss during post-retort drying of the BPANI coatings after retort $121{ }^{\circ} \mathrm{C}$ for $90 \mathrm{~min}$

\begin{tabular}{ll}
\hline Simulant & $\begin{array}{l}\text { Percent- } \\
\text { age loss }\end{array}$ \\
\hline DI Water & 23 \\
$1 \% \mathrm{NaCl}$ & 21 \\
$1 \%$ acetic, $1 \% \mathrm{NaCl}$ & 20 \\
$1 \%$ lactic & 25 \\
$0.25 \% \mathrm{NaCl}, 0.25 \%$ citric acid & 20 \\
\hline
\end{tabular}

of any coating applied to a given substrate. Adhesion quality under wet conditions after deformation is another phenomenon that must be investigated.

\section{Conclusion}

The study has shown chromium-coated steel without using $\mathrm{Cr}(\mathrm{VI})$ in the process offers dry adhesion levels which are comparable to commercially mature ECCS. The BPANI materials performed significantly lower than the benchmark epoxy-phenolic materials for dry adhesion. The retort performance dramatically reduced the adhesion performance of the BPANI materials on all the substrates. Hydrolysis of the BPANI has been proposed as the key mechanism for the reduction in the adhesion, as has absorption and permeation of the simulant solutions. With DI water, this process is almost entirely reversible with adhesion recovering under ambient conditions. The work has impact for can makers and fillers as it indicates that under high temperature and extended retort time, adhesion characteristics are changed. 
Fig. 10 Failure force relationship between the temperature of retort and the four substrate/ coating systems for the lactic acid simulant

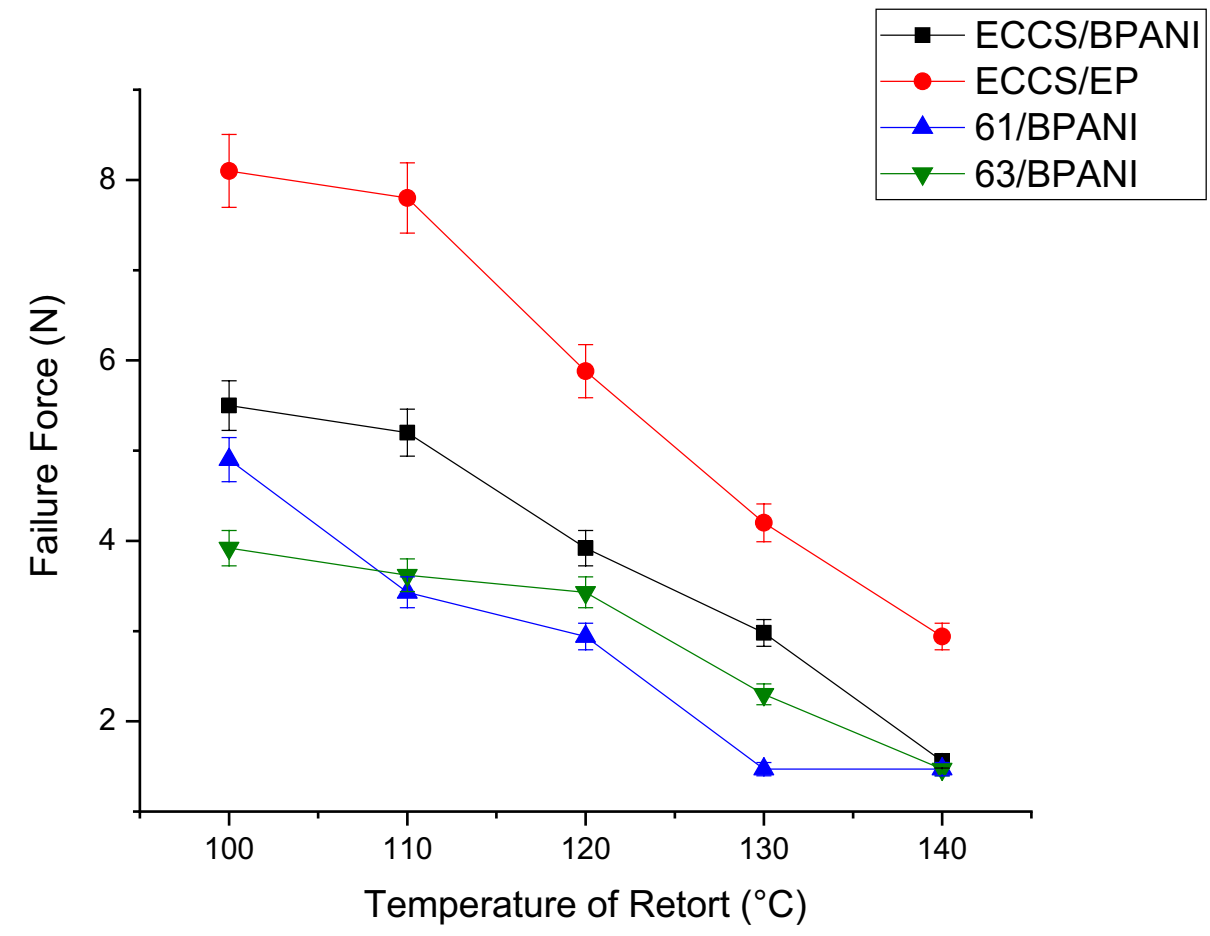

Acknowledgements The authors would like to thank TATA Steel Packaging Europe, CROWN Packaging Manufacturing UK Limited, European Social Fund via Welsh Government and EPSRC for supporting this work.

Open Access This article is distributed under the terms of the Creative Commons Attribution 4.0 International License (http://creativeco mmons.org/licenses/by/4.0/), which permits unrestricted use, distribution, and reproduction in any medium, provided you give appropriate credit to the original author(s) and the source, provide a link to the Creative Commons license, and indicate if changes were made.

\section{References}

1. Barilli F, Fragni R, Gelati S, Montanari A (2003) Study on the adhesion of different types of lacquers used in food packaging. Prog Org Coat 46:91-96. https://doi.org/10.1016/S0300 -9440(02)00215-1

2. Bishop CA (2015) Chapter 9-adhesion and adhesion tests. In: Vacuum deposition onto webs, films and foils. William Andrew, pp 197-208

3. Boelen B, den Hartog H, van der Weijde H (2004) Product performance of polymer coated packaging steel, study of the mechanism of defect growth in cans. Prog Org Coat 50:40-46. https://doi. org/10.1016/j.porgcoat.2003.09.011

4. BSI Standards (2011) BS EN ISO 1518-1:2011-paints and varnishes-determination of scratch resistance part $1-$ constant-loading method. https://www.iso.org/standard/59590.html. Accessed Oct 2016

5. Chen S (2015) The coating layer structure of commercial chrome plates. J Electron Spectrosc Relat Phenom 202:1-6. https://doi. org/10.1016/j.elspec.2015.01.006

6. da Rocha JC, da Cunha Ponciano Gomes JA, D’Elia E (2010) Corrosion inhibition of carbon steel in hydrochloric acid solution by fruit peel aqueous extracts. Corros Sci 52:2341-2348. https:// doi.org/10.1016/J.CORSCI.2010.03.033

7. Deák T (2014) Food technologies: sterilization. In: Motarjemi Y (ed) Encyclopedia of food safety, 1st edn. Academic Press, pp $245-252$

8. de Vooys A, Boelen B, Penning JP, van der Weijde H (2009) Improving coating resistance to acetic acid sterilisation: an EIS approach. Prog Org Coat 65:30-36. https://doi.org/10.1016/j. porgcoat.2008.09.004

9. Deflorian F, Rossi S (2003) The role of ions diffusion in the cathodic delamination rate of polyester coated phosphatized steel. J Adhes Sci Technol 17:291-306. https://doi.org/10.1163/15685 6103762302050

10. Jung JH, Ree M, Kim H (2006) Acid- and base-catalyzed hydrolyses of aliphatic polycarbonates and polyesters. Catal Today 115:283-287. https://doi.org/10.1016/j.cattod.2006.02.060

11. Knowles R, Meads R (2006) An analysis of the proposed REACH regulation. Regul Toxicol Pharmacol 44:24-32. https://doi. org/10.1016/j.yrtph.2005.07.007

12. Lee L-H (ed) (1980) Adhesion and adsorption of polymers. Springer, Boston

13. Leidheiser H, Wang W, Igetoft L (1983) The mechanism for the cathodic delamination of organic coatings from a metal surface. Prog Org Coat 11:19-40. https://doi.org/10.1016/00330655(83)80002-8

14. M'hiri N, Veys-Renaux D, Rocca E, Ioannou I, Boudhrioua NM, Ghoul M (2016) Corrosion inhibition of carbon steel in acidic medium by orange peel extract and its main antioxidant compounds. Corros Sci 102:55-62. https://doi.org/10.1016/j.corsc i.2015.09.017

15. Mannheim C, Passy N (1982) Internal corrosion and shelf-life of food cans and methods of evaluation. Crit Rev Food Sci Nutr 17:371-407. https://doi.org/10.1080/10408398209527354

16. Melvin C (2017) Fundamentals of adhesion for steel. PhD Thesis, Swansea University, UK (submitted) 
17. Montanari A, Pezzani A, Cassarà A, Quaranta A, Lupi R (1996) Quality of organic coatings for food cans: evaluation techniques and prospects of improvement. Prog Org Coat 29:159-165. https ://doi.org/10.1016/S0300-9440(96)00625-X

18. Paseiro-Cerrato R, Noonan GO, Begley TH (2016) Evaluation of long-term migration testing from can coatings into food simulants: polyester coatings. J Agric Food Chem 64:2377-2385. https://doi. org/10.1021/acs.jafc.5b05880

19. Pournaras AV, Prodromidis MI, Katsoulidis AP, Badeka AV, Georgantelis D, Kontominas MG (2008) Evaluation of lacquered tinplated cans containing octopus in brine by employing X-ray microanalysis and electrochemical impedance spectroscopy. J Food Eng 86:460-464. https://doi.org/10.1016/j.jfood eng.2007.09.034

20. Robertson GL (2016) Chapter 3-Metal packaging materials. In: Food packaging: principles and practice, 3 rd edn. CRC Press, pp 189-229
21. Sammon C, Yarwood J, Everall N (2000) An FT \pm IR study of the effect of hydrolytic degradation on the structure of thin PET films. Polym Degrad Stab 67:149-158

22. Teixeira AA (1994) Thermal processing: canning and pasteurization. In: Reference module in food science. https://doi. org/10.1016/B978-0-08-100596-5.02993-0

23. Vandenberg LN, Hauser R, Marcus M, Olea N, Welshons WV (2007) Human exposure to bisphenol A (BPA). Reprod Toxicol 24:139-177. https://doi.org/10.1016/j.reprotox.2007.07.010

24. Wijenberg JHOJ, Steegh M, Aarnts MP, Lammers KR, Mol JMC (2015) Electrodeposition of mixed chromium metal-carbide-oxide coatings from a trivalent chromium-formate electrolyte without a buffering agent. Electrochim Acta 173:819-826. https://doi. org/10.1016/j.electacta.2015.05.121

25. Yaro AS, Khadom AA, Wael RK (2013) Apricot juice as green corrosion inhibitor of mild steel in phosphoric acid. Alex Eng $\mathbf{J}$ 52:129-135. https://doi.org/10.1016/J.AEJ.2012.11.001 